\title{
The Learning Styles of College Aviation Students
}

\author{
Craig A. Kanske \\ Sky Views L.L.C. \\ L. Tom Brewster \\ Oklahoma State University-Tulsa
}

\begin{abstract}
This study investigated the learning styles of collegiate aviation students. The results of this investigation were compared to the learning styles of qualified pilots in the United States Air Force, as identified in a previous study. Using the Kolb Learning Style Inventory, the objectives were to identify the learning styles of collegiate aviation students, determine if there was a difference in learning style among the grade levels of the college students, and to note the similarities and/or differences in learning styles between the collegiate aviation students and the United States Air Force pilots. The demographic survey used in the previous study was tailored to reflect the disparity of experiences between college students and active pilots in the United States Air Force. The population for this study consisted of students enrolled in the aviation programs at Oklahoma State University-Stillwater campus, Oklahoma State University-Tulsa campus, and Southeastern Oklahoma State University on the Durant campus and at Tinker Air Force Base.

Using the results of this study to identify a preferred learning style among college aviation students can provide information about the students' cognitive mapping. This mapping can be used as a tool so that courses can be more effectively designed. Modifications to this main theme can then be made for those students who have different learning styles. An ideal learning style, due to the predictive nature of Kolb's Learning Style Inventory, can also identify aviation students as a discrete group from other degree programs on campus.
\end{abstract}

\section{INTRODUCTION}

Due to the importance of learning styles, Oklahoma legislators and educators are examining a program called Oklahoma Schools Attuned. Their goal is to train teachers to recognize and utilize the student's learning strengths (Levine, 2000). The concept of learning styles covers a broad spectrum of mental and physical processes. Learning styles focus on how a student learns, as opposed to the subject matter. Many people think of the physiological components of learning and approach the subject as a study of visual, auditory, tactile, and kinesthetic learners. Levine (2000) quotes Rita Dunn, professor of education and director of the Center for the Study of Learning and Teaching Styles at St. John's University, stating, "Without taking stock of our own learning style, many of us try to produce through our weaknesses" (pg. D-5). In this study, our goal was to identify the predominant cognitive learning style of college aviation students to provide a basis to extend this concept to these students. 
Schmeck (1988) attributes learning style development to a process of positive reinforcement during early learning situations. Continued success with a specific learning style, and the positive feelings of achievement this success brings, lead to a preference for a specific style, even when other styles may be more appropriate for specific subject matter. This process of transference from previous experiences is part of the experiential learning cycle.

Kolb (1984) breaks the cycle into four distinct steps: (a) concrete experience, or the ability to become involved " ... fully, openly, and without bias in new experience . ..", (b) reflective observation, or the ability ". . . to reflect on and observe . . . experiences from many perspectives . . .", (c) abstract conceptualization, or the ability to ". . . create concepts that integrate . . . observations into logically sound theories . . .", and (d) active experimentation, or the ability to ". . . use these theories to make decisions and solve problems ...." (p. 30). The process of acquiring knowledge becomes a spiral in which the learner moves from one step in the learning process to the next, building continuously on previous experiences.

Kolb (1984) describes the four basic steps in this cycle by using two sets of opposing choices: Vicarious experience and abstract conceptualization, which actively opposes participating in the event through concrete experience. The internalized reflective observation is opposed by the externalized active experimentation. The dichotomy between the abstract and the concrete thinker has entered the popular culture with the images of a concrete thinking, pocket protector wearing, leftbrained engineer and the longhaired, abstract-thinking artist coming readily to mind. The reflectively observing introvert and the actively experimenting extrovert are also readily identifiable as personalities.
These dichotomies make up Kolb's Learning Styles.

Kolb (1984, 1993) applies the concept of preferred learning styles to these two dichotomies to identify four different styles. The accommodator is a concretethinking extrovert who combines concrete experience and active experimentation, while the diverger is a concrete-thinking introvert combining concrete experience and reflective observation. On the opposite side of the scale are the converger, an abstractthinking extrovert combining abstract conceptualization and active experimentation; and the assimilator, the abstract-thinking introvert combining abstract conceptualization and reflective observation.

The Kolb Learning Style Inventory (LSI), developed in 1976, was revised in 1985, and 1993 to identify where in the learning cycle an individual's preferences fall. To complete the LSI, the subject ranks four possible endings for 12 sentence stems. This forced-ranking, where each ending identifies one of the four steps in the learning cycle, produces a score between 12 and 48 for each mode of learning. Two combination scores are derived to identify a preferred location along each of the two learning dichotomies: abstract/concrete and active/reflective. Subtracting the concrete experience score from the abstract conceptualization score and subtracting the reflective observation score from the active experimentation score, provides these two combination scores. Plotting these two combination scores on a learning-style grid will identify which quadrant best describes the preferred learning style of the subject (Kolb 1985,1993).

In addition to being revised twice since its development in 1976, Kolb's LSI has been validated over the years in such studies as a comparison of learning styles of high school and college students (Matthews 
\& Hamby, 1995) and a cross-cultural comparison between Western and Asian learners (Auyeng \& Sands, 1995). The LSI also is relatively easy to understand and administer. With only 12 forced-choice responses to complete, the instrument is quickly answered.

A survey of pilots in the United States Air Force (USAF) using Kolb's Learning Style Inventory and a demographic survey form was performed (Kanske, 1998/1999). In addition to describing an individual's primary learning style, the LSI displays some predictive ability. Because of the specialization of undergraduate degree programs, it is possible to " . . . expect to see relations between people's learning style and the early training they received in an educational specialty or discipline . . ." (Kolb, 1984, p.85). Kolb reports significant results for undergraduate education as a predictor of learning style, showing degrees in the arts going to divergers, degrees in the physical sciences going to convergers, and degrees in the social sciences going to assimilators.

The study of USAF pilots indicated no variation in learning style based upon undergraduate degree, with no significant variation in learning style when sorted for this factor. The converger style was identified as the preferred learning style among USAF pilots. The intent of the current study was to describe the learning styles of pilots within a common educational discipline, collegiate aviation students, using the methodology for determining learning styles developed in the study of USAF pilots. The research question was designed to determine if there was some point during college where this learning style becomes dominant, or if the learning styles of college aviation students and pilots in the United States Air Force are totally unrelated to each other.

The identification of a preferred learning style among college aviation students provides a focus for course design; allowing developers to design for the learning preference of the student population. Modifications to this main theme can then be adjusted to fit the needs of those students who have different learning styles. A preferred learning style, due to the predictive nature of Kolb's Learning Style Inventory, can also identify aviation students as a discrete group from other degree programs on campus.

\section{METHODOLOGY}

The population for this study consisted of students enrolled in the aviation programs at Oklahoma State UniversityStillwater campus, Oklahoma State University-Tulsa campus, and Southeastern Oklahoma State University on the Durant campus, and at Tinker Air Force Base. Kolb's Learning Style Inventory was used as the survey instrument. The demographic survey form was modified to account for the collegiate experience as opposed to the active military experience.

Surveys were distributed to students during the Fall 2000 semester at Oklahoma State University-Stillwater, and during the Spring 2001 semester at Oklahoma State University-Tulsa, Southeastern Oklahoma State University at Durant, and Tinker Air Force Base. Survey packages, including a cover letter, the demographic form, and the Learning Style Inventory, were distributed, and collected, by classroom instructors and at the flight facilities for each location.

\section{RESULTS AND ANALYSIS}

Responses were received from 74 students at Oklahoma State UniversityStillwater, (61.6\% response) 56 students at Oklahoma State University-Tulsa (46.7\% response), 41 students at Southeastern 
Oklahoma State University-Durant $(31.5 \%$ response), and 16 students from Tinker Air Force Base (32\% response). The grade level breakdown of this group of students is shown in Table 1. The limited number of lower division students from Tulsa is a result of a cooperative education program with Tulsa Community College. Southeastern Oklahoma State UniversityTinker students are primarily upper division. Lower division courses for Tinker Air Force students are obtained from either a local junior college or schools previously attended and are transferred into the Southeastern Oklahoma State University program. Some responses were unusable, due to errors such as no demographic data, missing responses on the Learning Style Inventory, and responses on the Learning Style Inventory with violated scoring criteria. Only useable survey responses are included in Table 1.

\section{Table 1}

Responses by Grade Level and School

\section{School}

$\begin{array}{ccccc}\begin{array}{ccc}\text { SOSU } \\ \text { Durant }\end{array} & \begin{array}{c}\text { OSU } \\ \text { Stillwater }\end{array} & \begin{array}{c}\text { SOSU } \\ \text { Tinker AFB }\end{array} & \text { OSU } & \\ \text { Tulsa } & \underline{\text { Totals }}\end{array}$

Grade

Freshman

Sophomore

Junior

Senior

Graduate Student

Totals
8

7

10

11

0

36
16

14

23

15

2

70

0
2
5
2
7
16

1

2

23

15

12

53
25

25

61

43

21

175

\section{LEARNING STYLE ANALYSIS}

Instruments were scored using the methods outlined in the Learning-Style Inventory Self-Scoring Inventory and Interpretation Booklet (Kolb, 1993). This method produced scores for concrete experience, reflective observation, abstract conceptualization, and active experimentation for each subject. From these four raw scores, two combination scores, abstract conceptualization minus concrete experience (AC-CE) and active experimentation minus reflective observation (AE-RO), were derived. The final step in the analysis is to plot the intersection of the two combination scores on a grid using AE-RO as the $\mathrm{X}$-axis and $\mathrm{AC}-\mathrm{CE}$ as the Y-axis. The quadrant on the grid in which the intersection falls was used to define the subjects' learning style.

The predominant learning style 
displayed by the college students, using this scoring method, was assimilator, with 62 students. This represents 36.7 percent of the surveys with valid learning styles. The diverger learning style was least represented among the responding students with only 26 students, 15.4 percent. The accommodator style was the second most prominent with 39 students or 23.1 percent, followed by the converger style with 42 students and 24.9 percent. These results are shown in Table 2.

Table 3 summarizes the learning styles of the study group, broken down by grade level. Among the freshman class, 25.0 percent were divergers, 33.3 percent accommodators, 20.8 percent convergers, and 20.8 percent assimilators. Convergers and assimilators represented 77.8 percent of the sophomore class, and the remaining 22.2 percent were accommodators or divergers. The junior class had 64.3 percent convergers/assimilators and 35.7 percent accommodators/divergers, while the senior class had $61.0 \quad$ percent convergers/assimilators and 39.0 percent accommodators/divergers. Finally, 66.7 percent of graduate students were convergers/assimilators and only 33.3 percent were accommodators/divergers.

The results for group learning styles derived with the calculations of AE-RO and AC-CE used to define learning styles are shown in Table 5. Means for the total sample of AE-RO equal 4.56 and AC-CE equal 5.82 plot in the assimilator style. Freshmen, with an AE-RO of 5.58 and an AC-CE of 2.41 plot in the diverger style. The sophomores' AE-RO of 6.00 and AC$\mathrm{CE}$ of 10.56 plots in the converger style. An AE-RO of 6.30 and AC-CE of 5.63 for juniors also plots in the converger style. Means of 2.49 for AE-RO and 6.27 for AC$\mathrm{CE}$ plot in the assimilator style for seniors. Finally, graduate students plot in the assimilator style with means for AE-RO of 1.19 and AC-CE of 5.29.

\section{ANALYSIS AND CONCLUSIONS}

The overall look at the learning styles of the students surveyed was similar to the results of the U.S. Air Force pilot study. Perhaps most striking is the similarity in the percentages of respondents with either the assimilator or converger learning styles. These two groups made up 67.8 percent of the U.S. Air Force study group (Kanske, 1998/1999) and 61.5 percent of the college study group.

The Kolb learning style inventory, for a random population, will produce an equal distribution among the four learning styles. The total sample of this study showed a significant deviation $(\mathrm{p}<0.0013)$ from equal distribution with a tendency toward abstract-conceptualization. The distribution of freshman learning styles matches that of a random population. At the sophomore level, a strong distribution $(\mathrm{p}<0.09)$ toward assimilator and converger was observed. The small sample size for the sophomores is a cause for concern, and future data must be obtained before this distribution can be considered truly significant. Junior level student responses skewed toward converger and assimilator $(\mathrm{p}<0.11)$. Assimilator was the dominant style among seniors at $41 \%$ with $\mathrm{p}<0.11$ and graduate students at $52 \%(\mathrm{p}<0.036)$.

College aviation students start out with a random population distribution of learning styles, but migrate toward the assimilator or converger style. These styles of learning remain the dominant styles throughout the aviation experience. Since all U.S. Air Force pilots are required to have a college degree, they closely match the graduate student classification of this study. It should be noted that the Air Force study (Kanske, 1998/1999) percentage (67.8\%) closely matches the $66.7 \%$ result for graduate students from this study.

Martin (2000) found a shift in style 
after the sophomore year, and suggested that this shift deserved further study. This study found the shift to occur even earlier, after the freshman year. This growing body of data recognizes a shift in learning style as aviation students progress through their education. Why this happens is, as yet, unanswered.

In an effort to answer this question, we consider this the first step in a multi-year study of aviation students. By tracking the learning styles of aviation students, we hope to determine if there are changes of individual learning styles, or if individuals with "non-predominant learning styles" tend to self eliminate from aviation programs. 


\section{Table 2}

Style by school

Learning Style

\begin{tabular}{ccccc} 
& \multicolumn{2}{c}{ School } & & \\
OSU & OSU & SOSU & SOSU & \\
Stillwater & $\underline{\text { Tulsa }}$ & $\underline{\text { Durant }}$ & $\underline{\text { Tinker AFB }}$ & $\underline{\text { Totals }}$
\end{tabular}

Diverger

Accommodator

Converger

Assimilator

Totals
12

15

18

21

66
9

8

14

21

52
4

11

7

14

36
1

5

3

6

15
26

39

42

62

169

\section{Table 3}

Style by current standing (percentage)

\section{Current Standing}

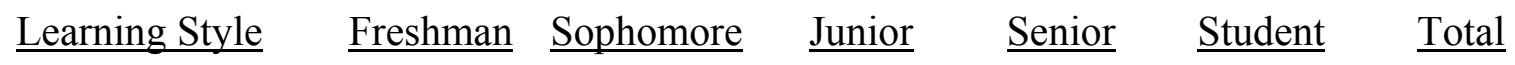

$\begin{array}{lllllll}\text { Diverger } & 25.0 & 5.6 & 12.5 & 19.5 & 14.3 & 15.4\end{array}$

\begin{tabular}{|c|c|c|c|c|c|}
\hline Accommodator & 33.3 & 16.7 & 23.2 & 19.5 & 19.0 \\
\hline Converger & 20.8 & 33.3 & 33.9 & 19.5 & 14.3 \\
\hline Assimilator & 20.8 & 44.4 & 30.4 & 41.5 & 52.4 \\
\hline $\begin{array}{l}\text { Diverger } \\
\quad+ \\
\text { Accommodator }\end{array}$ & 58.3 & 22.2 & 35.7 & 39.0 & 33.3 \\
\hline $\begin{array}{c}\text { Converger } \\
+\end{array}$ & 41.7 & 77.8 & 64.3 & 61.0 & 66.7 \\
\hline
\end{tabular}




\title{
Table 4
}

Style by current standing (frequency)

\section{$\underline{\text { Current Standing }}$}

\begin{tabular}{|c|c|c|c|c|c|c|}
\hline Learning Style & $\underline{\text { Freshman }}$ & $\underline{\text { Sophomore }}$ & $\underline{\text { Junior }}$ & $\underline{\text { Senior }}$ & $\begin{array}{c}\text { Graduate } \\
\text { Student }\end{array}$ & $\underline{\text { Totals }}$ \\
\hline Diverger & 6 & 1 & 7 & 8 & 3 & 25 \\
\hline Accommodator & 8 & 3 & 13 & 8 & 4 & 36 \\
\hline Converger & 5 & 6 & 19 & 8 & 3 & 41 \\
\hline Assimilator & 5 & 8 & 17 & 17 & 11 & 58 \\
\hline Totals & 24 & 18 & 56 & 41 & 21 & 160 \\
\hline
\end{tabular}

\section{Table 5}

Mean Values for:

Active Experimentation minus Reflective Observation (AE-RO) and Abstract Conceptualization minus Concrete Experience (AC-CE)

\section{Current Standing}

$\underline{\text { Scale }}$

Freshman

\author{
Sophomore
}

$\underline{\text { Junior }}$

$\underline{\text { Senior }}$

Graduate

$\underline{\text { Overall }}$

Student $\quad \underline{\text { Mean }}$

Active

Experimentatio

$\mathrm{n}$ minus

Reflective

5.58

6.00

6.30

2.48

1.19

4.56

Observation

(AE-RO)

Abstract

Conceptualizati

on minus

Concrete

2.41

10.56

5.63

6.27

5.28

5.82

Experience

(AC-CE) 


\section{REFERENCES}

Auyeng, P., \& Sands, J. (1996, November). A cross-cultural study of the learning styles of accounting students. Accounting and Finance, 36 (2), 261-275.

JMP-IN Edition 3.1.5 [computer software]. (1995). Cary, NC: SAS Institute, Inc.

Kanske, C. A. (1998/1999). The learning styles of pilots currently qualified in United States Air Force aircraft (Doctoral dissertation, Oklahoma State University, Aviation and Space Program 1998). Dissertation Abstracts International, 9918799.

Kolb, D. A. (1984). Experiential learning: Experience as the source of learning and development. Englewood Cliffs, N.J.: Prentice-Hall.

Kolb, D. A. (1985). Learning-Style Inventory: Self-Scoring Inventory and Interpretation Booklet. Boston: Hay/McBer Training Resources Group.

Kolb, D. A. (1993). Learning-Style Inventory: Self-Scoring Inventory and Interpretation Booklet (Revised scoring). Boston: Hay/McBer Training Resources Group.

Levine, I. (2000, December 19). Learning styles key to improving academic performance, experts say. Tulsa World, pp. D1, D5.

Martin, R. A. (2000). The relationship of document and quantitative literacy with learning styles and selected personal variables for aviation university students. Collegiate Aviation Review (18), 1. 26-40.

Matthews, D. B., \& Hamby, J V. (1995, March-April). A comparison of the learning styles of high school and college university students. The Clearing House, 69 (4), 249 (6).

Schmeck, R. R. (Ed.). (1988). Learning strategies and learning styles. New York, N.Y.: Plenum Press.

Statistica Release 5.1 [computer software]. (1997). Tulsa, OK: StatSoft, Inc. 